\title{
Challenges and opportunities in refugee mental health: clinical, service, and research considerations
}

\author{
Matthew Hodes ${ }^{1} \cdot$ Dimitris Anagnostopoulos ${ }^{2} \cdot$ Norbert Skokauskas $^{3}$
}

Published online: 13 February 2018

c) Springer-Verlag GmbH Germany, part of Springer Nature 2018

\section{Background}

For generations, persecution and war have resulted in the movement of people across international borders within Europe, into Europe, and across many other international borders [1]. Continuing conflict especially in the Middle East and Central Asia, North Africa, and the Horn of Africa has caused many people to be displaced. Most displaced people and refugees are from low income countries, and the increased number of refugees since the onset of the Syrian war in 2010 with ongoing war in Iraq has created an international humanitarian disaster [2]. Nevertheless, the arrival of 2.68 million refugees into Europe in 2015 and 2016 (Eurostat, accessed 2nd September 2017) has been perceived as a crisis with major political, economic, social, and health dimensions. Amongst the sectors that are tested by crises and need to respond is health care, including the mental health services, in view of the anticipated high level of need.

The mental health of asylum seekers and refugees has been investigated in many studies over the last 2 decades, with increasing number of publications since the 1990s. The studies converge in many key findings. First, they show that children and adolescents, as well as parents and other family members who are displaced and become refugees, have a high level of exposure to war events and privation even

This article is part of the focused issue 'Mental health issues in refugees'.

Matthew Hodes

m.hodes@imperial.ac.uk

1 Centre for Psychiatry, Hammersmith Hospital Campus, Imperial College London, 7th Floor Commonwealth Building, Du Cane Road, London W12 0NN, UK

2 Department of Child and Adolescent Psychiatry, Medical School, National and Kapodistrian University of Athens, Athens, Greece

3 Norwegian University of Science and Technology, NTNU, Trondheim, Norway prior to migration [2-4]. Recent wars reveal the appalling level of war exposure, including witnessing deaths of family, experience of combat and injury, and abuse including sexual violence of the refugees relevant for those arriving in Europe in 2015-2016 [5-7]. These adverse experiences may continue during what are often hazardous journeys in pursuit of safety. The refugees who reach resettlement countries may experience a continuing high level of adverse events associated with legal uncertainties, detention and deportation, financial hardship, social isolation, and language and employment problems, even after they have obtained legal right to remain [4]. Second, these are risk factors for psychiatric disorders such as PTSD, depression, and anxiety disorders, which may be persistent [4, 8, 9]. Nevertheless, there are significant variations in the prevalence of disorders that are associated with variation in exposure to the range of adversities. Third, many people including youngsters exposed to adverse events do not develop psychiatric disorders, and show a high level of resilience. Some studies have even found that refugees can have a lower rate of disorders than same age peers in the host population [10]. However, it is crucial to consider how that resilience might be promoted to achieve optimal well-being. This requires understanding of the complex interplay between past and ongoing risk factors, cultural (including religious) and family influences and the societal response to the recently arrived refugees, an area that requires further investigation [11].

The influx of many refugees into Europe in 2015-2016 with awareness from earlier studies of their likely high levels of psychological distress and mental health needs prompted the European Society of Child and Adolescent Psychiatry (ESCAP) and its affiliated journal European Child and Adolescent Psychiatry to focus on the societal and mental health implications of the refugee crisis. The ESCAP position statement urged governments and other agencies to intervene to prevent the exposure of children and families to war, and when this does happen, to provide higher levels of support and interventions to reduce psychological distress and promote social 
function and well-being [12]. ESCAP sought to become active in disseminating information about the mental health of refugees and established an ESCAP online forum (http://www. escap.eu/care/organizing-the-knowledge-to-sup-port-menta 1-health-care-for-refugee-children/) [13]. One proposal arising from this initiative was to develop a focused issue of European Child and Adolescent Psychiatry, which appears here.

\section{Social consequences of the increased refugee migration to Europe 2015-2016}

The first paper [14] gives further information about the refugees coming to Europe and the policy response and knowledge of mental health of six European countries (Turkey, Greece, Germany, UK, Sweden, and Norway). These countries have been selected as they lie along the routes following departure from Iraq and Syria and taken by the migrating refugees in their pursuit of a safe haven and a better life. However, the countries are heterogeneous with regard to their past histories of receiving refugees, the numbers coming to each in association with crisis of 2015-2016, and their health care systems and responses. It is accepted that this paper does not provide a comprehensive account of all European countries and the recent experiences of some other countries are available elsewhere [15].

The data from Eurostat show that in the year April 2016-March 2017, the top countries from which refugees came to EU countries were (numbers in brackets): Syria $(245,530)$, Afghanistan $(154,325)$, Iraq $(100,225)$, Nigeria $(51,230)$, Pakistan $(43,705)$, Eritrea $(34,245)$, and Iran $(34,740)$. The data show that the refugees come from diverse cultures, as well as being culturally and linguistically different from the host communities they arrive in and in which they resettle. They often settle in cities and regions that have experienced a significant immigration of earlier groups of refugees and economic migration. Their arrival at a time, following austerity, when there has also been an increase of terrorism with radical Islamic links has further complicated the attitudes of populations and response by politicians and policy makers. The recent years have witnessed a rise of right wing anti-immigrant populist parties across Europe. It has been argued that this is the "perfect storm" in terms of changed European attitudes and perceptions that have become increasingly ambivalent and often hostile towards refugees [16].

\section{Hostility to asylum seekers}

There are significant consequences of negative attitudes to refugees that can be seen at multiple levels, each of which can have implications for mental health. At an interpersonal level, increased hostility leads to more frequent "micro-aggressions", characterised by aggressive, racist or hostile speech and other acts, as well as more overt expressions of racism, all of which increase psychological distress and risk for psychiatric disorder [17-19]. An interesting population survey carried out in Germany investigated attitudes of adolescents and adults to unaccompanied refugee minors (URM) probably the most vulnerable group [20]. The results showed heterogeneity of response. Only $23 \%$ or respondents thought Germany could accommodate more URM, but more than 50\% thought URM from the Balkans and Africa should be returned, and 34\% fully or partly agreed URM from the Middle East should be returned there. It is unknown whether the attitudes would be different in other European countries. More aggressive than hostile speech and attitudes is physical violence against asylum seekers. In Germany in 2016, following the large influx of asylum seekers into the country, there were 10 attacks per day, resulting in injuries to 560 people, including 43 children (see http://www.bbc.co.uk/news/ world-europe-390968330). Data regarding aggression and attacks on refugees in other European countries are not as readily accessible and this may represent a knowledge gap.

At a state level, harsher and more hostile governmental policies to asylum seekers may result in stricter barriers to entry and high rates of unsuccessful asylum applications. A case in point is the UK's "moral failure to admit refugee children", the headline in the staid Financial Times (February 12th, 2017), linked to the government's refusal in 2016 to join the EU plan to resettle 160,000 across the bloc and further obstacles to supporting asylum seekers. More harsh attitudes are also reflected in the use of detention for immigration purposes and often used prior to deportation. Consistent with this is the finding that the UK has one of the largest detained populations of asylum seekers in the EU. Detention has been reported for years to be an adversity that increases psychological distress and risk of psychiatric disorder, with studies carried out predominantly with adolescents and adults [21, 22]. This is a notoriously difficult population to investigate, as even gaining access can be restricted by government policy [23]. An innovation is the original report in this issue of a study of children aged 3-13 years who had experienced immigration detention with family members for variable lengths of time [24]. This nuanced qualitative study revealed the persistent effects manifest in play but reflecting mental states and preoccupation with the themes of confinement, loss of protection, and violence. These are experiences that appear detrimental to well-being, and in combination with the effects of detention on parental mental health and parent child interaction, suggest mechanisms for possible increased rates of psychopathology. Also reported in this issue is a community-based study from Australia, confirming that detention is associated 
with increased psychological distress and risk of disorder amongst groups of asylum seeking children [25].

\section{Family and cultural influences on adjustment}

The refugees arriving in Europe come from countries with different cultures than those found in the countries in which they settle. Their cultural adaptation requires various strategies, one of which is acculturation, the process by which they acquire the culture, values, and language of the host society [26]. Recent perspectives accept that this process involves acquisition of new cultures without abandonment of the culture of origin, so that immigrants, and especially the young population, become flexibly multicultural [27]. The study reported in this issue regarding Somali Bantu refugees settled in USA [28] describes the family processes associated with these changes. In particular, the parental experience of loss of culture and pain of exile and parent-child misappraisals suggest how the seeds for conflict, emotional distance, and low adolescent support could arise and contribute to psychopathology. The important influence of parental psychological distress on child adjustment is revealed in the study of Syrian refugee parent-child pairs recruited from schools in Turkey. While as expected trauma predicted children's posttraumatic stress symptoms, predictors of general childhood psychological distress included parental factors (but not trauma) [29].

While it is accepted that refugees have a high level of resilience, a considerable minority will need access to mental health services. In this setting, socio-cultural influences are also important, in view of the link between the migration history, asylum issues, and culturally shaped perception of distress and disorder and attitudes to intervention [30]. This serves as a useful reminder that the encounter between western mental health services and refugees is itself an intercultural encounter, for which appropriate knowledge and reflection is required [31].

\section{Unaccompanied refugee minors}

There have been numerous reports that unaccompanied minors are at high risk of psychological distress and psychiatric disorder, but most studies have significant methodological problems such as small sample size and potentially ascertainment bias [8]. It is gratifying to see the rigorous population-based study from Denmark [32]. This reports higher incidence rates of psychiatric disorders (all categories combined and neurotic disorders, in ICD-10 terms) amongst unaccompanied minors than accompanied refugees. There has been concern how best to help this vulnerable group.
The review of treatment studies for psychiatrically distressed unaccompanied refugee minors is very revealing in demonstrating the dearth of adequate studies with this group [33], although cognitive behavioural approaches with individuals or groups look promising [34] and interventions that give meaning to the events (psychoeducation, rapport building, and use of narratives) could also be effective [35]. The potential for offering the interventions to large groups and ensuring that the unaccompanied minors find them rewarding and effective and can make sense of the interventions is also important [36].

\section{Future research}

This focused issue highlights some aspects of the experiences of refugees in resettlement countries following flight from war, organized violence, and community destruction. The papers address salient adversities and protective factors for psychological distress. Unaccompanied asylum seeking minors are particularly vulnerable. Surprisingly, little is known about psychiatric epidemiology, help seeking and best interventions, and health care systems for this new influx of young refugees. Urgent attention is needed to address these deficiencies, and this requires action at local, national, and international levels.

\section{References}

1. Kushner T, Knox K (1999) Refugees in an age of genocide. Frank Cass, London

2. UNHCR (2016) Global trends. Forced displacement in 2015 (Geneva UNHCR). p 68

3. UNHCR (2000) The state of the world's refugees 2000. Oxford University Press, Oxford

4. Priebe S, Giacco D, El-Nagib R, WHO Health Evidence Network Synthesis Reports (2016) Public health aspects of mental health among migrants and refugees: a review of the evidence on mental health care for refugees, asylum seekers and irregular migrants in the WHO European Region. WHO Regional Office for Europe, Copenhagen

5. Arsenijevic J, Schillberg E, Ponthieu A, Malvisi L, Ahmed WAE, Argenziano S, Zamatto F, Burroughs S, Severy N, Hebting C et al (2017) A crisis of protection and safe passage: violence experienced by migrants/refugees travelling along the Western Balkan corridor to Northern Europe. Confl Health 11:6

6. Cetorelli V, Sasson I, Shabila N, Burnham G (2017) Mortality and kidnapping estimates for the Yazidi population in the area of Mount Sinjar, Iraq, in August 2014: a retrospective household survey. PLoS Med 14:e1002297

7. Stark L, Asghar K, Yu G, Bora C, Baysa AA, Falb KL (2017) Prevalence and associated risk factors of violence against conflict-affected female adolescents: a multi-country, cross-sectional study. J Glob Health 7:010416

8. Fazel M, Reed RV, Panter-Brick C, Stein A (2012) Mental health of displaced and refugee children resettled in high-income 
countries: risk and protective factors. Lancet (London, England) 379:266-282

9. Reed RV, Fazel M, Jones L, Panter-Brick C, Stein A (2012) Mental health of displaced and refugee children resettled in lowincome and middle-income countries: risk and protective factors. Lancet (London, England) 379:250-265

10. Vaage AB, Tingvold L, Hauff E, Ta TV, Wentzel-Larsen T, Clench-Aas J, Thomsen PH (2009) Better mental health in children of Vietnamese refugees compared with their Norwegian peers-a matter of cultural difference? Child Adolesc Psychiatry Mental Health 3:34

11. Silove D, Ventevogel P, Rees S (2017) The contemporary refugee crisis: an overview of mental health challenges. World Psychiatry Off J World Psychiatr Assoc (WPA) 16:130-139

12. Anagnostopoulos DC, Heberbrand J, Eliez S, Doyle MB, Klasen $\mathrm{H}$, Crommen S, Cuhadaroglu FC, Pejovic-Milovancevic M, Herreros O, Minderaa R et al (2016) European Society of Child and Adolescent Psychiatry: position statement on mental health of child and adolescent refugees. Eur Child Adolesc Psychiatry 25:673-676

13. Hebebrand J, Anagnostopoulos D, Eliez S, Linse H, Pejovic-Milovancevic M, Klasen H (2016) A first assessment of the needs of young refugees arriving in Europe: what mental health professionals need to know. Eur Child Adolesc Psychiatry 25:1-6

14. Hodes M, Vasquez MM, Anagnostopoulos D, Triantafyllou K, Abdelhady D, Weiss K, Koposov R, Cuhadaroglu FC, Hebebrand J, Skokauskas N (2017) Refugees in Europe: national overviews from key countries with a special focus on child and adolescent mental health. Eur Child Adolesc Psychiatry. https://doi. org/10.1007/s00787-017-1094-8

15. Milovancevic MP, Ispanovic V, Stupar D (2016) Lessons learned from the past on mental health care of refugee children in Serbia. Eur Child Adolesc Psychiatry 25:669-672

16. Lucassen L (2017) The refugee crisis in historical perspective. In: InZentIM-Congress "Key elements of model communities for refugees and immigrants_-an interdisciplinary perspective" June 21-23, 2017 (Essen)

17. Aichberger MC, Bromand Z, Rapp MA, Yesil R, Montesinos AH, Temur-Erman S, Heinz A, Schouler-Ocak M (2015) Perceived ethnic discrimination, acculturation, and psychological distress in women of Turkish origin in Germany. Soc Psychiatry Psychiatr Epidemiol 50:1691-1700

18. Elias A, Paradies Y (2016) Estimating the mental health costs of racial discrimination. BMC Public Health 16:1205

19. Hatch SL, Gazard B, Williams DR, Frissa S, Goodwin L, Hotopf M (2016) Discrimination and common mental disorder among migrant and ethnic groups: findings from a South East London Community sample. Soc Psychiatry Psychiatr Epidemiol 51:689-701

20. Plener PL, Groschwitz RC, Brahler E, Sukale T, Fegert JM (2017) Unaccompanied refugee minors in Germany: attitudes of the general population towards a vulnerable group. Eur Child Adolesc Psychiatry. https://doi.org/10.1007/s00787-017-0943-9

21. Hodes M (2010) The mental health of detained asylum seeking children. Eur Child Adolesc Psychiatry 19:621-623

22. Robjant K, Robbins I, Senior V (2009) Psychological distress amongst immigration detainees: a cross-sectional questionnaire study. Br J Clin Psychol 48:275-286
23. Sen P, Arugnanaseelan J, Connell E, Katona C, Khan AA, Moran P, Robjant K, Slade K, Tan J, Widyaratna K et al (2017) Mental health morbidity among people subject to immigration detention in the UK: a feasibility study. Epidemiol Psychiatr Sci 1-10. https ://doi.org/10.1017/S2045796017000269

24. Kronick R, Rousseau C, Cleveland J (2017) Refugee children's sandplay narratives in immigration detention in Canada. Eur Child Adolesc Psychiatry. https://doi.org/10.1007/s00787-017-1012-0

25. Zwi K, Mares S, Nathanson D, Tay AK, Silove DM (2017) The impact of detention on the social-emotional wellbeing of children seeking asylum: a comparison with community based children. Eur Child Adolesc Psychiatry. https://doi.org/10.1007/s0078 7-017-1012-0

26. Berry JW (2001) A psychology of immigration. J Soc Issues 57:615-631

27. Schwartz SJ, Unger JB, Zamboanga BL, Szapocznik J (2010) Rethinking the concept of acculturation: implications for theory and research. Am Psychol 65:237-251

28. Frounfelker RL, Assefa MT, Smith E, Hussein A, Betancourt TS (2017) We would never forget who we are: resettlement, cultural negotiation, and family relationships among Somali Bantu refugees. Eur Child Adolesc Psychiatry. https://doi.org/10.1007/s0078 7-017-0991-1

29. Eruyar S, Maltby J, Vostanis P (2017) Mental health problems of Syrian refugee children: the role of parental factors. Eur Child Adolesc Psychiatry. https://doi.org/10.1007/s00787-017-1101

30. O'Driscoll VJ, Serneels G, Imeraj L (2017) A file study of refugee children referred to specialized mental health care: from an individual diagnostic to an ecological perspective. Eur Child Adolesc Psychiatry. https://doi.org/10.1007/s00787-017-0981-3

31. Ang W (2017) Bridging culture and psychopathology in mental health care. Eur Child Adolesc Psychiatry 26:263-266

32. Norredam ML, Nellums M, Nielson RR, Byberg S, Petersen JH (2017) Incidence of psychiatric disorders among accompanied and unaccompanied asylum seeking children in Denmark-a nationwide register-based cohort study. Eur Child Adolesc Psychiatry. https://doi.org/10.1007/s00787-018-1122-3

33. Demazure G, Gaultier S, Pinsault N (2017) Dealing with difference: a scoping review of psychotherapeutic interventions with unaccompanied refugee minors. Eur Child Adolesc Psychiatry. https://doi.org/10.1007/s00787-017-1083-y

34. Brown RC, Witt A, Fegert JM, Keller F, Rassenhofer M, Plener PL (2017) Psychosocial interventions for children and adolescents after man-made and natural disasters: a meta-analysis and systematic review. Psychol Med 47(11):1893-1905

35. Brown FL, de Graaff AM, Annan J, Betancourt TS (2017) Annual Research Review: breaking cycles of violence-a systematic review and common practice elements analysis of psychosocial interventions for children and youth affected by armed conflict. J Child Psychol Psychiatry 58:507-524

36. Sarkadi A, Adahl K, Stenvall E, Ssegonja R, Batti H, Gavra P, Fangstrom K, Salari R (2017) Teaching Recovery Techniques: evaluation of a group intervention for unaccompanied refugee minors with symptoms of PTSD in Sweden. Eur Child Adolesc Psychiatry. https://doi.org/10.1007/s00787-017-1093-9 